\title{
Hybrid Melody valve implantation in the tricuspid position in a 2.5-year-old boy with hypoplastic left heart syndrome
}

\author{
Piotr Stanek', Grzegorz Zalewski', Luiza Zalewska², Agnieszka Skierska², Beata Kutek³, Lesław Szydłowski³, \\ Jacek Kusa ${ }^{3}$
}

'Department of Pediatric Cardiac Surgery, John Paul II Upper Silesian Child Health Center in Katowice, Katowice, Poland

2Department of Pediatric Cardiology, John Paul II Upper Silesian Child Health Center in Katowice, Katowice, Poland

${ }^{3}$ Department of Pediatric Cardiology, Faculty of Medical Sciences, Medical University of Silesia in Katowice, Katowice, Poland

\author{
Correspondence to: \\ Luiza Zalewska, MD \\ Department of Pediatric \\ Cardiology, \\ John Paul II Upper Silesian Child \\ Health Center, \\ Medyków 16, 40-754 Katowice, \\ Poland, \\ phone: +48 660582632 \\ e-mail: \\ luizakamilazalewska@gmail.com \\ Copyright by the Author(s), 2021 \\ Kardiol Pol. 2021; \\ 79 (11): 1292-1293. \\ DOI: 10.33963/KP.a2021.0110 \\ Received: \\ April 16, 2021 \\ Revision accepted: \\ September 11, 2021 \\ Published online: \\ September 13, 2021
}

Tricuspid valve function has a significant impact on the systemic circulation and thus the survival and functional status of a patient after univentricular palliation of hypoplastic left heart syndrome [1]. Infants and young children with tricuspid regurgitation have limited options for prosthetic valve replacement due to the size of the tricuspid annulus ( $<15 \mathrm{~mm}$ ).

A new perspective in this area of pediatric surgery is the use of a stented bovine jugular vein graft (Melody valve) with the intention of further valve expansion in the cath lab as the child grows [2]. In young children, the Melody valve is predominantly implanted in the mitral position $[2,3]$. Still, there are few data describing tricuspid valve replacement. We present a case of successful hybrid implantation of a Melody valve in the tricuspid position in a patient with single ventricle circulation.
A 2.5-year-old boy with hypoplastic left heart syndrome and sick sinus syndrome, after cardiac surgery treatments including a bidirectional Glenn shunt, was admitted to the cardiac department due to heart failure. Transthoracic echocardiography followed by transesophageal echocardiography revealed massive tricuspid regurgitation with a reduced cardiac output (Figure 1A). Tricuspid insufficiency had been present since birth. However, due to structural dysfunction of the valve, tricuspid regurgitation had markedly deteriorated over time. Despite the intensification of heart failure treatment, the child's general condition failed to improve, and he was scheduled for surgery. The size of the atrioventricular annulus ( $14 \mathrm{~mm}$ ) limited prosthetic options. A hybrid procedure involving Melody valve implantation in the tricuspid
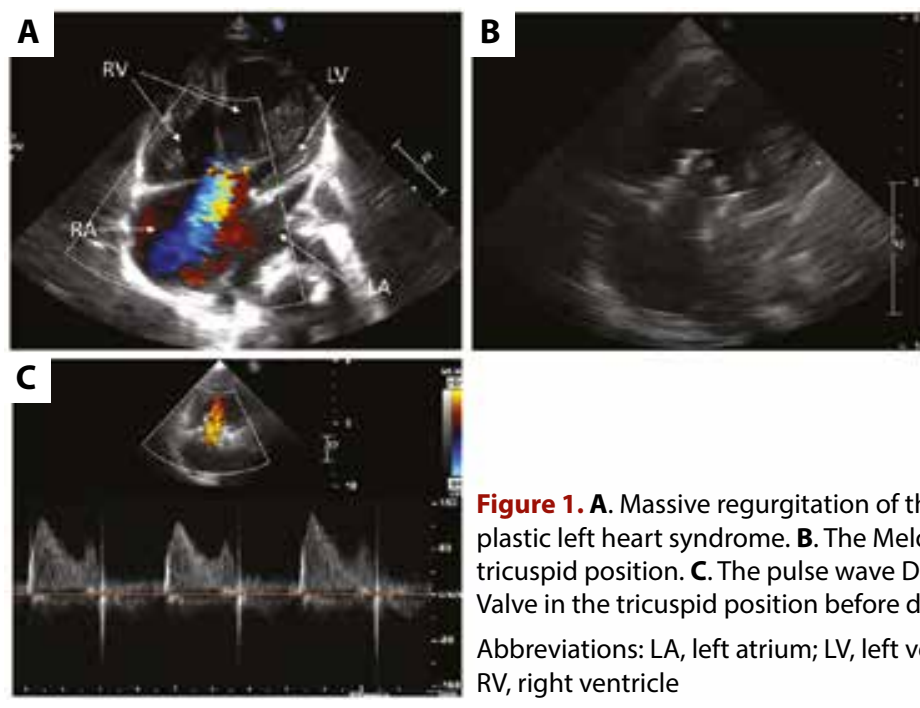

Figure 1. A. Massive regurgitation of the tricuspid valve in hypoplastic left heart syndrome. B. The Melody Valve implanted in the tricuspid position. C. The pulse wave Doppler flow of the Melody Valve in the tricuspid position before discharge

Abbreviations: LA, left atrium; LV, left ventricle; RA, right atrium; $\mathrm{RV}$, right ventricle 
position by the right atriotomy was performed. Single Prolene 5-0 sutures were placed on the atrioventricular valve annulus. The structures of the valve leaflets and subvalvular apparatus were left untouched. In the first stage of the Melody valve implantation, the stent was shortened by folding the distal edges on both sides. The valve was then mounted on a high-pressure balloon (Atlas gold) of a $20-\mathrm{mm}$ diameter. However, during the inflation of the balloon, it moved outside the valve annulus. Therefore, the valve was mounted on a low-pressure balloon (Tyshak II) with a 20-mm diameter. During the inflation of the balloon, an optimal valve position was obtained. The valve was placed in the atrioventricular position using continuous sutures while reducing the diameter of the atrioventricular annulus. The patient underwent epicardial pacemaker implantation at the time of Melody valve implantation.

The postoperative period was complicated by endocarditis, which was treated efficiently with antibiotics. At discharge, the mean echocardiographic Doppler gradient of the Melody valve in the tricuspid position was $3 \mathrm{~mm} \mathrm{Hg}$, and regurgitation was mild (Figure 1B, C). During 18 months of follow-up, valvular function remained stable, thus the Fontan procedure was performed.

Severe tricuspid regurgitation, which is a risk factor for mortality in children undergoing palliative procedures for hypoplastic left heart syndrome, can be reduced by successful tricuspid valve procedures [4]. Melody valve placement in the atrioventricular valve position is a new alternative in valve surgery for the youngest and most challenging patients with single ventricle who require surgical valve interventions.

\section{Article information}

Conflict of interests: None declared.

Open access: This article is available in open access under Creative Common Attribution-Non-Commercial-No Derivatives 4.0 International (CC BY-NC-ND 4.0) license, allowing to download articles and share them with others as long as they credit the authors and the publisher, but without permission to change them in any way or use them commercially. For commercial use, please contact the journal office at kardiologiapolska@ptkardio.pl.

How to cite: Stanek P, Zalewski G, Zalewska L, et al. Hybrid Melody valve implantation in the tricuspid position in a 2.5 -year-old boy with hypoplastic left heart syndrome. Kardiol Pol. 2021; 79(11): 1292-1293, doi: 10.33963/KP.a2021.0110.

\section{REFERENCES}

1. Tsang VT, Raja SG. Tricuspid valve repair in single ventricle: timing and techniques. Semin Thorac Cardiovasc Surg Pediatr Card Surg Annu. 2012; 15(1): 61-68, doi: 10.1053/j.pcsu.2012.01.010, indexed in Pubmed: 22424509.

2. Pluchinotta FR, Piekarski BL, Milani V, et al. Surgical atrioventricular valve replacement with Melody valve in infants and children. Circ Cardiovasc Interv. 2018; 11(11): e007145, doi: 10.1161/CIRCINTERVENTIONS.118.007145, indexed in Pubmed: 30571200.

3. Haponiuk I, Chojnicki M, Paczkowski K, et al. Pediatric Melody mitral valve replacement in acute endocarditis: 2 consecutive cases operatedon with an alternative hybrid technique. Kardiol Pol. 2020; 78(1): 75-77, doi: 10.33963/KP.15132, indexed in Pubmed: 31922500.

4. Ruzmetov M, Welke $K$, Geiss $D$, et al. Outcomes of tricuspid valve repair in children with hypoplastic left heart syndrome. J Card Surg. 2014; 29(5): 698-704, doi: 10.1111/jocs.12414, indexed in Pubmed: 25081042. 